\section{Pattern of growth of a gastric inflammatory fibroid polyp with PDGFRA overexpression}

A 73-year-old man with esophageal varices due to hepatitis $C$ virus-induced cirrhosis has been followed by endoscopy since 1994. When a smooth, flat elevation first appeared in the gastric antrum in 2004 ( Fig. 1 a), our provisional diagnosis was gastric verrucosa.

Follow-up endoscopy over the next 2 years showed no remarkable change, but in 2007 the lesion grew bigger ( Fig. 1 b) and a small ulcer appeared on the apex in March 2008 ( Fig. 1c). Mesenchymal tumors such as gastrointestinal stromal tumor or malignant lymphoma were suspected but biopsy was inconclusive. After another 6 months the ulcer had extended downward ( Fig. 1d) and exhibited the characteristic gross appearance of an inflammatory fibroid polyp (IFP). The polyp, removed endoscopically, was composed of spindle cells arranged in an onionskin-like concentric formation in the submucosal layer, accompanied by inflammatory cell infiltration, which predominantly consisted of eosinophils ( Fig. 2).

On immunohistochemistry, the spindle cells were diffusely positive for PDGFRA (platelet-derived growth factor receptor $\alpha$ ) ( Fig. 3), focally positive for CD34, and negative for KIT.

These findings were consistent with those of the classical IFP with concentric formation [1].

IFP is a rare mesenchymal tumor of the gastrointestinal tract and its natural history is unknown [2]. Our report demonstrates that it might take several years for gastric IFP to grow from an endoscopically discernible elevation into the characteristic submucosal tumor. Follow-up endos-
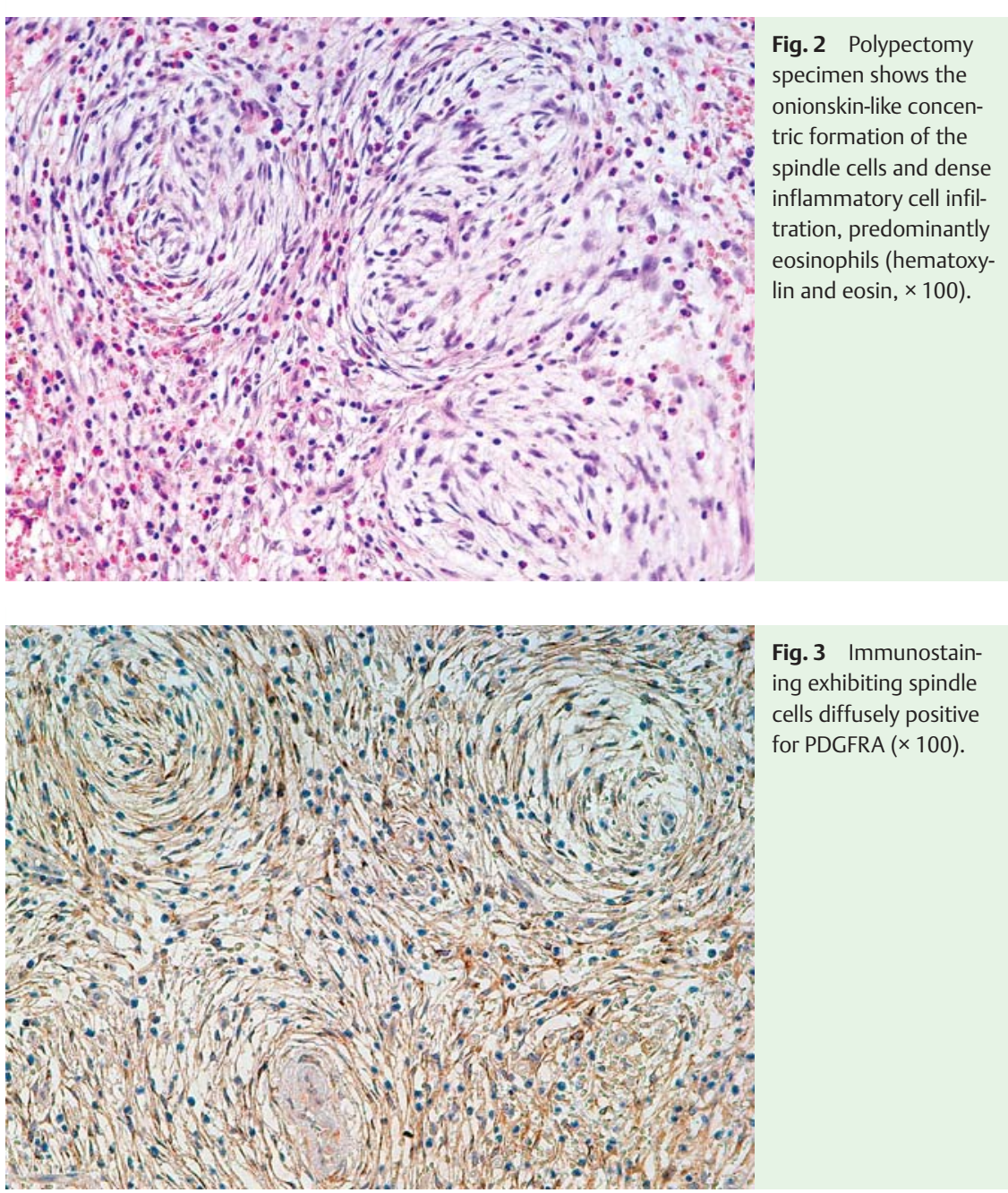

Fig. 3 Immunostaining exhibiting spindle cells diffusely positive for PDGFRA $(\times 100)$.
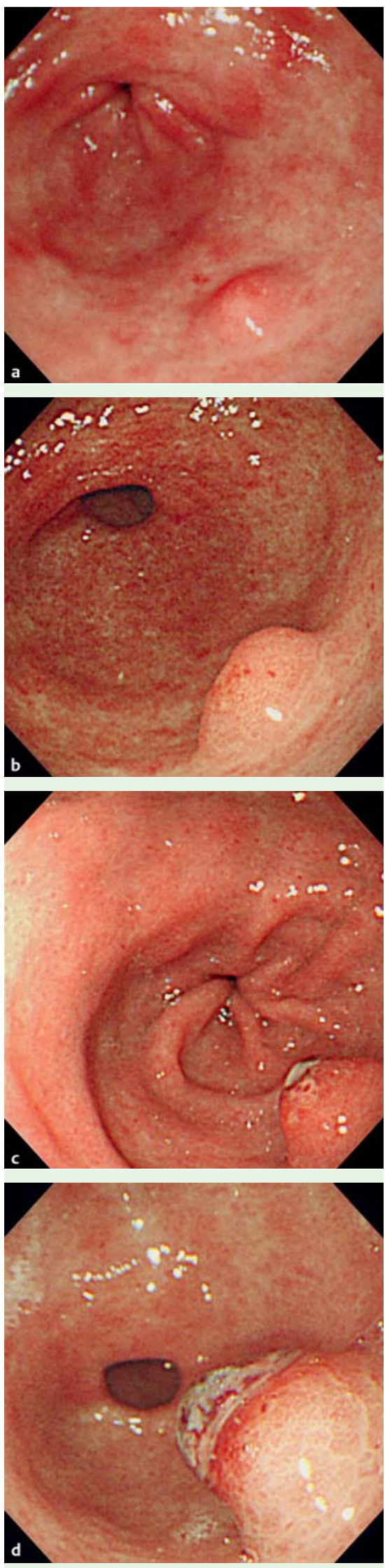

Fig. 1 Pattern of growth of the gastric polyp. Endoscopic appearance in a 2004, b 2007, c March 2008, and d September 2008, which shows the findings representative for inflammatory fibroid polyp. 
copy enabled not only the establishment of the correct diagnosis before resection but also endoscopic treatment before surgical intervention became inevitable. Since the first description by Vanek [3] in 1949, IFP has been regarded as a reactive polyp rather than a neoplastic lesion. In 2008, however, a seminal study by Schildhaus et al. first demonstrated ubiquitous PDGFRA overexpression and frequent gain-of-functional PDGFRA mutation in IFPs [1]. These findings, supported by subsequent studies $[4,5]$, point to the neoplastic nature of IFP and the current case supports a crucial role for PDGFRA activation in gastric IFP.

Endoscopy_UCTN_Code_CCL_1AB_2AD_3AB

Competing interests: None
K. Yamashita', Y. Arimura ${ }^{1}$, T. Tanuma ${ }^{1}$, T. Endo ${ }^{2}$, T. Hasegawa ${ }^{3}$, Y. Shinomura ${ }^{1}$

1 First Department of Internal Medicine, Sapporo Medical Univeristy, Sapporo, Japan

2 Sapporo Shirakaba-dai Hospital, Sapporo, Japan

3 Department of Clinical Pathology, Sapporo Medical University, Sapporo, Japan

\section{References}

1 Schildhaus HU, Cavlar T, Binot E et al. Inflammatory fibroid polyps harbour mutations in the platelet-derived growth factor receptor alpha (PDGFRA) gene. J Pathol 2008; 216: 176- 182

2 Bhatti I, Melhado R, Leeder $P$ et al. Clinical challenges and images in GI. Image 3: Inflammatory fibroid polyp. Gastroenterol 2008; 135: 1465, 1808

3 Vanek J. Gastric submucosal granuloma with eosinophilic infiltration. Am J Pathol 1949; 25: $397-411$
4 Daum O, Hatlove J, Mandys V et al. Comparison of morphological, immunohistochemical, and molecular genetic features of inflammatory fibroid polyps (Vanek's tumors). Virchows Arch 2010; 456: 491 - 497

5 Lasota J, Wang ZF, Sobin LH et al. Gain-offunction PDGFRA mutations, earlier reported in gastrointestinal stromal tumors, are common in small intestinal inflammatory fibroid polyps. A study of 60 cases. Mod Pathol 2009; 22: 1049-1056

Bibliography

DOI $10.1055 / \mathrm{s}-0030-1256289$

Endoscopy 2011; 43: E171 -E172

(c) Georg Thieme Verlag KG Stuttgart · New York . ISSN 0013-726X

\section{Corresponding author}

\section{K. Yamashita}

First Department of Internal Medicine Sapporo Medical University

S1W16 Chuo-ku

Sapporo 060-8543

Japan

Fax: +81-11-611-2282

ykentaro@sapmed.ac.jp 